\title{
Materials Researchers Must Work with Policymakers and the Public to Garner Support for Nanotechnology
}

As I write this article, the United States House of Representatives has just passed the Nanotechnology Research and Development Act of 2003, legislation I authored with House Science Committee Chair Sherwood Boehlert (R-N.Y.), by an overwhelming vote of 405-19. Thanks to my interactions with members of the Materials Research Society (MRS), I am well aware of the impact that nanotechnology is having and will continue to have on the field of materials science and engineering.

The National Nanotechnology Initiative (NNI) was formally created with President Bill Clinton's fiscal year 2001 budget request, and President George Bush has continued to support it. The NNI provides loose coordination of the nanotechnology research and development (R\&D) efforts of 13 federal agencies, including the National Science Foundation, the Department of Defense, the Department of Energy, and the National Aeronautics and Space Administration (NASA).

One of my first experiences with nanotechnology came in early 2002 when I visited the nanotechnology center at NASA Ames Research Center in Silicon Valley. When I returned to Washington D.C., I began developing nanotechnology legislation with the 2001-2002 MRS/ Optical Society of America Congressional Fellow, Eric Werwa, who was working in my office. Werwa encouraged me to attend the 2002 MRS Spring Meeting, where I had the chance to meet MRS members who are actively participating in cutting-edge nanotechnology work. The conversations we had were invaluable in helping me to understand the potential of nanotechnology and the need to help advance the field for the wellbeing of our society, as well as for that of my Silicon Valley congressional district.

In June 2002, the National Research Council published the report, "Small Wonders, Endless Frontiers: A Review of the National Nanotechnology Initiative." This report cited the value of interagency collaboration on nanotechnology, but also made several recommendations on how this coordination could be improved. One observation in the report was that academic and industrial researchers from outside the agencies participating in the NNI are not involved in the policymaking process. To address this, it was proposed in the report that an independent advisory board consisting of industrial and academic members provide advice to the

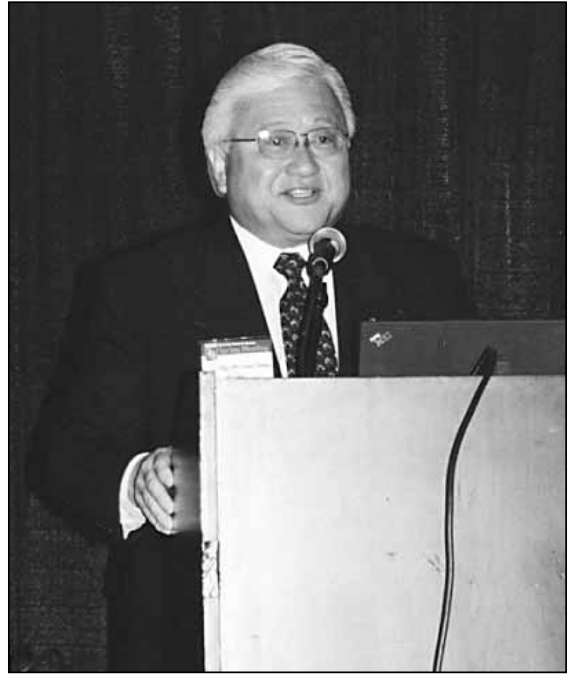

Rep. Michael M. Honda (D-Calif.) at the 2002 Materials Research Society Spring Meeting in San Francisco.

president and the agencies. The report also recommended that greater attention be paid to the societal implications of nanotechnology.

In October 2002, I introduced H.R. 5669, the Nanoscience and Nanotechnology Advisory Board Act, to implement the recommendation of the NRC panel. This bill, which expired at the end of 2002, was only the first step toward addressing the country's nanotechnology needs. Researchers in the field expressed their concern to me that, since the NNI is not authorized in law by Congress, any president could choose not to continue the program.

To undertake this task, Rep. Boehlert and I introduced the Nanotechnology Research and Development Act (H.R. 766). In addition to containing provisions from H.R. 5669, the bill authorizes nearly $\$ 2.4$ billion in spending over the next three years on nanotechnology R\&D (see Table I). After introducing the bill, our committee held two hearings. At the first hearing on the federal investment in nanotechnology R\&D, members of Congress learned much about nanotechnology $R \& D$ that materials researchers already know. One particular point that was made was the need for federal support for commercialization of nanotechnology, which was addressed by an amendment I offered during the committee's mark-up of the bill.

The second hearing on societal implications of nanotechnology covered topics that are probably broader in scope than what materials researchers deal with in their work, but which are essential in gaining public acceptance of nanotechnology. Not surprisingly, Michael Crichton's novel Prey (HarperCollins, 2002) was mentioned, as members of Congress wanted to know how much of the book was fiction and how much could actually happen. While scientists are well aware of what is possible and policymakers are learning, the general public has neither the field expertise of scientists nor the opportunities to learn that are afforded to policymakers. Many of their impressions regarding new technologies are formed by what they see on television and in movies or read in books, leading to impressions that are based more on fiction than on fact.

This has proven to be a big problem in the field of genetically modified organisms, especially in Europe. The general public has a vastly different impression of this technology than do the scientists who developed it, and as such will not purchase genetically modified products. The vast investment of intellectual and financial resources to develop these products goes unrewarded largely for reasons that 
are not completely grounded in science, but which cannot be dealt with rationally at this point.

Since nanotechnology is still a field in its infancy, we have a chance to address some of the possible unintended consequences before they occur.

There is a great lesson to be learned from this case for those in the field of nanotechnology. It is essential that scientists and engineers reach out to the general public and explain what this field is all about. It is also essential that policymakers demonstrate to the public that we recognize that there are both benefits and possible risks associated with nanotechnology, and that we are taking care to pay attention to both of these areas. Since nanotechnology is still a field in its infancy, we have a chance to address some of these possible unintended consequences before they occur-unlike what happened with genetically modified foods. It is my intention to make sure that policymakers do this. I call upon you, the scientists and engineers, to play your part in this process and educate the public about nanotechnology.

REP. MichaEl M. HONDA

Michael M. Honda (D-Calif.) serves on the U.S. House of Representatives Committee on Science, specifically on the subcommittees of research and of energy.

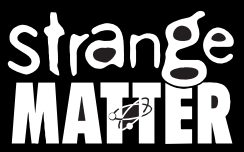

\section{MRIS}

For their generous support of the

Strange Matter project, the Materials Research Society would like to thank the following:

National Science Foundation

Cillin: Alcan

Dow Dow

(F) Ford Motor Company

E.1 3M Foundation
Are you ready for a close encounter with the amazing world of modern materials?

\section{Come explore the} strange matter behind everyday stuff... Go ahead, touch it!

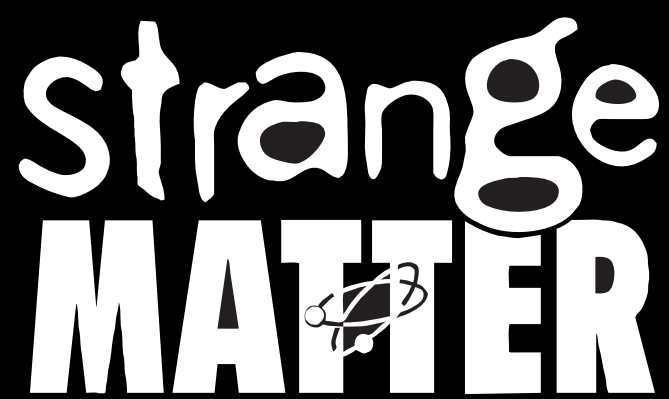

\section{We dare you.}

Enter the fascinating world of materials and uncover the surprising science behind everyday stuff. High-tech fields like the space program are known for their use of advanced materials, but these materials have also found their way into the stuff of everyday life-from car shock absorbers and eyeglass frames, to DVD players and golf clubs.

\section{Strange Matter previews to the general public June 28, 2003 - January 4, 2004 Ontario Science Centre, Toronto, Canada}

Explore Strange Matter and catch a glimpse of where the future of materials research might lead. Materials under investigation include memory metals, crystals, polymers, ferrofluids and amorphous metals. You'll discover what gives these materials their intriguing and often surprising properties. And don't miss the exhibition theater! Demonstrations with cutting-edge materials are sure to educate and fascinate.

Presented by the Materials Research Society, Strange Matter features 5000 -square feet of interactive experiences designed and fabricated by the Ontario Science Centre, under contract to the Materials Research Society.

For more information on Strange Matter, including future exhibition dates and locations, visit our interactive Web site at www.strangematterexhibit.com.

\section{Volunteers!}

Starting in February 2004, Strange Matter may be traveling to a city near you and volunteers will be needed. Interested in working with a host science center or local schools? Do you have media interests or contacts? If so, contact Amy Moll at amoll@boisestate.edu to discuss volunteer opportunities.

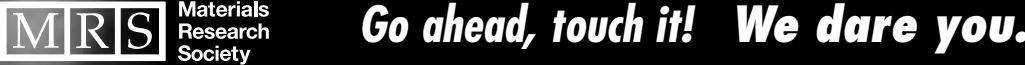

